\title{
Gout secondary to chronic renal disease: studies on urate metabolism
}

\author{
LEIF B. SORENSEN \\ From the Department of Medicine, Pritzker School of Medicine, University of Chicago, Chicago, Illinois \\ 60637, USA
}

SUMMARY A report of 20 cases of gout considered to be secondary to chronic renal disease is presented. Studies of renal function and of uric acid metabolism were carried out in 16 patients. The daily production of urate remained within normal limits in the face of progressive renal dysfunction. Renal excretion of uric acid was decreased to a mean of $35.5 \%$ of the turnover. The cumulative urinary recovery of intravenously injected ${ }^{14} \mathrm{C}$-uric acid averaged $32.0 \%$. In 3 patients ${ }^{14} \mathrm{C}$ was successively retrieved in urinary allantoin and urea, in carbon dioxide of expired air, and in faeces. As in normal man, carbon dioxide and ammonia were the principal uricolytic products. The extrarenal excretion of uric acid assumes a greater role in chronic renal disease and eventually becomes the major route of elimination of uric acid. The possibility that gout may be secondary to intrinsic renal disease should be entertained when azotaemia is present.

Moderate hyperuricaemia frequently occurs early in the course of chronic renal disease. In such patients a positive correlation exists between the serum urate and the serum creatinine concentrations. ${ }^{1}$ However, as renal function further deteriorates, plasma urate level is likely to remain between 0.42 and $0.54 \mathrm{mmol} / 1$ until the glomerular filtration rate has fallen to $15 \mathrm{ml}$ per minute. Despite the persistent mild hyperuricaemia in intrinsic chronic renal disease, acute gouty arthritis is generally thought to be a rare complication. Among 496 patients with chronic renal insufficiency Sarre ${ }^{2}$ found only 2 in whom gout was clearly a complication of chronic nephropathy. Richet et al. ${ }^{3}$ reported 17 cases of secondary gout among 1600 patients with chronic renal disease. This complication was observed during the course of renal diseases of long duration. Certain varieties of renal disease appear to be associated with an increased incidence of gout, e.g., chronic lead nephropathy, ${ }^{45}$ polycystic kidney disease, ${ }^{6} 7$ and renal amyloidosis. ${ }^{3}$

This communication reports 20 cases of gout considered to be secondary to primary renal disease. Studies of uric acid kinetics were performed in 16 of these patients in order to assess changes in urate metabolism due to chronic renal disease.

Accepted for publication 14 September 1979 Correspondence to Professor Sorensen.

\section{Patients and methods}

Sixteen patients participating in metabolic studies were maintained on a diet essentially free of purines for 5 days before as well as during the study. All drugs were discontinued 2 weeks prior to the study. Plasma and urinary uric acid was determined by an enzymatic spectrophotometric method. ${ }^{8}$ On the sixth day ${ }^{14} \mathrm{C}$-2-uric acid was injected intravenously in a dose of 20 to $40 \mu \mathrm{Ci}$. Uric acid was isolated from the urine and purified as described elsewhere. ${ }^{9}$ Radioassay of ${ }^{14} \mathrm{C}$ was done either in a vibrating reed electrometer after wet oxidation of uric acid in a vacuum combustion line ${ }^{9}$ or in a liquid scintillation spectrophotometer by the following technique: Preweighed amounts of uric acid were dissolved in $2 \mathrm{ml}$ hyamine hydroxide, then mixed with $18 \mathrm{ml}$ of a mixture of PPO (2,5-diphenyloxazole), $3 \mathrm{~g}$, POPOP (1, 4-bis-2-(5-phenyloxazolyl)benzene), $100 \mathrm{mg}$, and toluene, $1000 \mathrm{ml}$. In this system ${ }^{14} \mathrm{C}$-toluene counted with an efficiency of approximately $70 \%$. All samples were corrected for a modest degree of quenching, either by including internal standards or by applying a factor derived from a curve relating quenching to sample weight. Urate pool and turnover data were calculated by the isotope dilution principle.

The extent to which ${ }^{14} \mathrm{C}$ could be recovered in 
degradation products of uric acid was studied in 3 patients. The methods for determination of ${ }^{14} \mathrm{C}$ in urinary allantoin and urea, in carbon dioxide of expired air, and in faeces have been reported in detail. ${ }^{9}$ No attempt was made to isolate allantoic acid, since the $\mathrm{pH}$ of the urine of these 3 patients was less than 6 , and allantoic acid is known to degrade spontaneously to urea and glyoxylic acid at $\mathrm{pH}$ below $7 \cdot 3$.

In 12 patients renal function was determined by the clearance of inulin, in 3 by the clearance of creatinine and in 1 by the level of serum creatinine. Inulin clearance studies were carried out in the morning after a 12-hour fast. Each subject underwent aggressive oral hydration with tap water before and during the study. After administration of a priming dose, inulin was infused intravenously at a constant rate with a Harvard pump in a dose calculated to equal the estimated clearance rate. Urethral catheterisation was avoided in 6 patients. In the remaining 6 urine was collected through an indwelling Foley catheter with air washout to insure complete collection. All catheterisations were performed with stringent aseptic technique utilising Neosporin ointment as a lubricant. Urine cultures 24 hours and 1 week after each study were sterile. Clearance periods varied from 10 to 30 minutes, and a minimum of 3 clearance periods were employed for each study. Inulin analyses were carried out according to the method of Roe et al. ${ }^{10}$ Informed consent was obtained from each patient.

A summary of the clinical features of patients studied is presented in Table 1 . All 16 patients had experienced attacks of acute gouty arthritis. Two patients, both women, had tophaceous deposits, Crystals of monosodium urate were demonstrated by compensated polarised light microscopy in 13 cases. Nephropathy preceded the onset of gouty arthritis in all but 1 patient (case 13).

The aetiology of the primary renal disease was verified by post-mortem examination (cases 5, 8, 9, 12,14 , and 15); raised urinary lead levels, with or without stimulation by calcium disodium edetate (cases 1, 2, and 3); radiographically (cases 6 and 7); and by haemoglobin electrophoresis (case 10). Case 16 developed haemorrhagic nephritis after ingestion of turpentine oil; renal biopsy several years later showed focal chronic interstitial nephritis. Case 4 had a history of scarlatina, chorea, and kidney disease with oliguria in early childhood. Case 11 had been known to have accelerated essential hypertension for 6 years before developing his first attack of acute gouty arthritis. He died after an arterial graft replacement. Permission for necropsy was not granted. Case 13 had been studied by Dr Bartter at the Hypertension-Endocrine Branch,
National Heart and Lung Institute, NIH, 7 years previously, when his creatinine clearance was $61 \mathrm{ml} /$ min. This patient is case 2 in a series of 9 patients with Bartter's syndrome reported by that laboratory. ${ }^{11}$ Detailed accounts of the clinical histories of patients with lead nephropathy and sickle cell anaemia have been published elsewhere..$^{12} 13$

Cases 17 to 20 were not studied in detail. They have been included in this series because they serve as illuminating examples of gouty arthritis in chronic renal failure.

\section{CASE 17}

A 66-year-old woman presented with acute arthritis of the left first metatarsophalangeal joint, extending to the dorsum of the foot. Aspiration yielded $0.5 \mathrm{ml}$ of milky fluid which under polarised light contained negatively birefringent crystals. Plasma urate concentration was $0.56 \mathrm{mmol} / 1$ and serum urea nitrogen was $14.6 \mathrm{mmol} / \mathrm{l}$. Sixteen years previously, the patient underwent removal of 3 hyperplastic parathyroid adenomas, one of them weighing close to $30 \mathrm{~g}$. At the time of surgery multiple bilateral interstitial renal calcifications were present. Prior to surgery serum calcium had ranged between 3.52 and $3.90 \mathrm{mmol} / \mathrm{l}$ and serum phosphorous between 0.61 and $0.90 \mathrm{mmol} / \mathrm{l}$.

\section{CASE 18}

A 56-year-old woman was seen in the outpatient clinic for acute arthritis of the right ankle. Swelling and redness were present. $3 \mathrm{ml}$ of inflammatory fluid was aspirated from the subtalar joint. Intracellular negatively birefringent crystals were present. The patient had experienced 5 similar episodes during the preceding 3 years. Mild hypertension had been noted off and on for 5 years, and during the past year she had taken hydrochlorothiazide. Laboratory tests revealed a plasma urate of 0.85 $\mathrm{mmol} / \mathrm{l}$ while on the diuretic and $0.81 \mathrm{mmol} / \mathrm{l}$ off medication. Serum calcium was $3 \cdot 15$ and $3 \cdot 10$ $\mathrm{mmol} / \mathrm{l}$ and serum inorganic phosphorous 0.87 and $0.81 \mathrm{mmol} / \mathrm{l}$. Parathyroid hormone level was elevated at $1.9 \mathrm{ng} / \mathrm{ml}$ compared to an upper normal value of $1 \cdot 2 \mathrm{ng} / \mathrm{ml}$. Serum urea nitrogen was $17 \cdot 1$ $\mathrm{mmol} / \mathrm{l}$. The urine contained $3.27 \mathrm{mmol}$ of uric acid in a 24-hour period, and urate clearance was $2 \cdot 8 \mathrm{ml} / \mathrm{min}$. The patient refused surgical exploration of the neck for primary hyperparathyroidism.

\section{CASE 19}

A 64-year-old woman presented with acute inflammation of the metatarsophalangeal and interphalangeal joints of the left big toe. Synovial analysis showed numerous negatively birefringent crystals mainly inside polymorphonuclear leucocytes. 


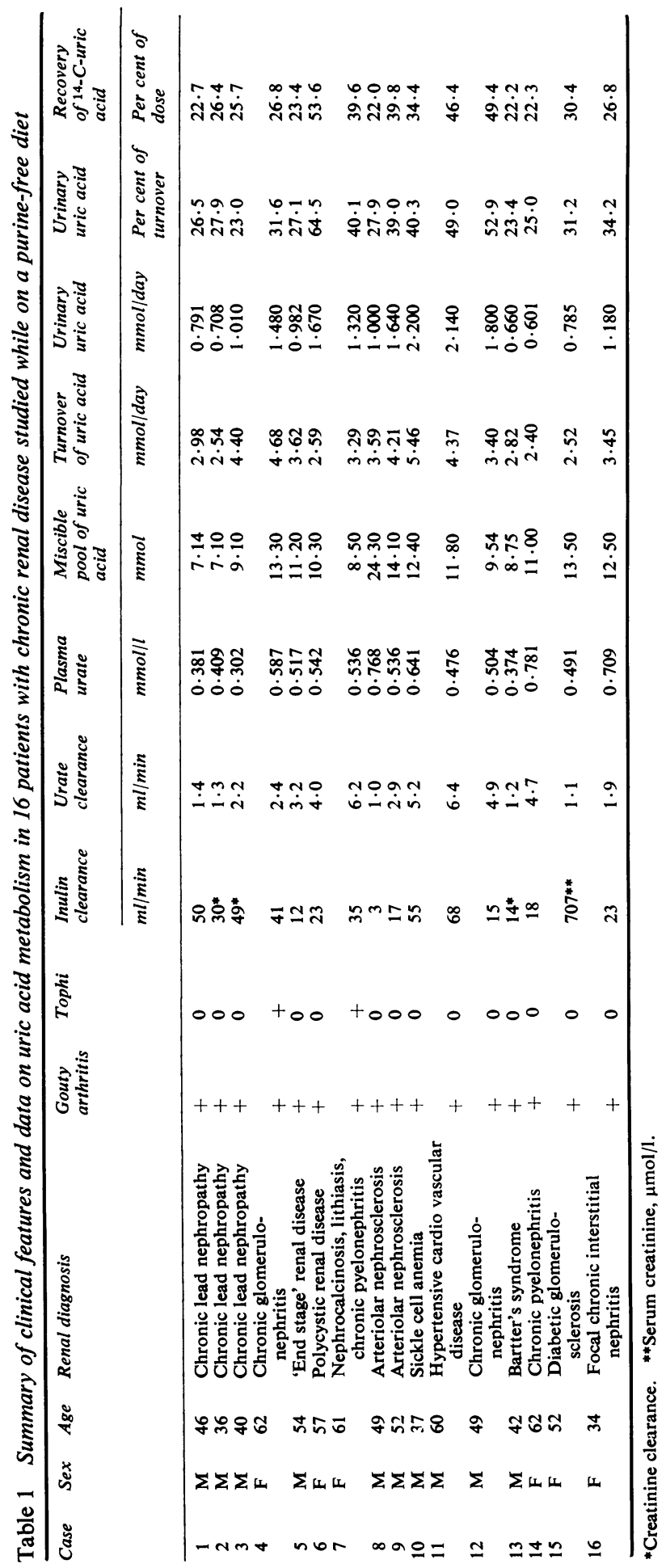


During the preceding 2 years she had experienced 3 similar attacks localised to the first metatarsophalangeal joints. The history was significant for several congenital abnormalities, including complete absence of the left kidney, and recurrent urinary tract infections. On a purine-low diet plasma urate concentration was $0.46 \mathrm{mmol} / \mathrm{l}$, urinary uric acid $2 \cdot 12 \mathrm{mmol} / 24 \mathrm{~h}$, urate clearance $3.21 \mathrm{ml} / \mathrm{min}$, and creatinine clearance $42 \mathrm{ml} / \mathrm{min}$ with a serum creatinine of $141 \mu \mathrm{mol} / \mathrm{l}$.

\section{CASE 20}

A 55-year-old woman was admitted to hospital for fatigue, malaise, weight loss, and intermittent left flank pain of 10 months' duration. During the preceding 12 years she had had multiple episodes of dysuria and urinary frequency for which she had been treated with sulphonamides. A diagnosis of gouty arthritis based on 2 attacks of acute inflammation of the left foot, promptly responding to colchicine, and associated with hyperuricaemia, was made 2 years earlier. Serum urea nitrogen was $15 \cdot 4$ $\mathrm{mmol} / \mathrm{l}$ and plasma urate $0.613 \mathrm{mmol} / \mathrm{l}$. Urine analysis revealed 15 to 18 leucocytes per high power field. Retrograde pyelograms showed bilateral hydronephrosis with narrowing of the left ureter. An inferior vena cavagram showed displacement and encroachment upon the inferior vena cava by a retroperitoneal process. Since the BUN continued to rise it was felt that the indwelling ureteral catheters did not provide adequate drainage. Surgical exploration showed the ureters to be embedded in a thick fibrous tissue, which was partly excised. To ensure adequate drainage bilateral nephrostomies were performed. However, the BUN continued to rise and the patient succumbed to uraemia and superimposed infection. The anatomical diagnosis was retroperitoneal fibrosis.

\section{Results}

A summary of data on the miscible pool, daily turnover, and urinary excretion of uric acid in 16 patients with chronic renal disease is presented in Table 1 . The clearance rate of inulin ranged from 3 to $68 \mathrm{ml} / \mathrm{min}$. Despite significant reduction in glomerular filtration the miscible pool of uric acid was only modestly raised, far less than that of other nitrogenous waste products.

Three patients with chronic lead nephropathy had plasma urate levels below $0.42 \mathrm{mmol} / \mathrm{l}$ while on a purine-free diet. On a regular diet plasma urate levels rose by $0.12 \mathrm{mmol} / \mathrm{l}$. A similar rise in plasma urate with the addition of exogenous purines has been noted in patients with saturnine gout. ${ }^{14}$

The daily turnover of uric acid was normal in all patients except for the patient with sickle cell anaemia, who had a uric acid production of 5.46 $\mathrm{mmol} /$ day, a value which is about $40 \%$ higher than expected on the basis of his weight. An increased production of uric acid is not unexpected in a patient with chronic haemolytic anemia.

The urinary excretion of uric acid ranged from 22.9 to $64 \cdot 2 \%$ of the uric acid produced, with a mean value of $35.5 \%$. The cumulative urinary excretion of injected ${ }^{14} \mathrm{C}$-uric acid is shown in Fig. 1 for the first 13 subjects and in Figs. 2, 3, and 4 for the remaining 3 patients. The urinary recovery of ${ }^{14} \mathrm{C}$-uric acid varied from 22.0 to $53.6 \%$ of the administered dose, the average value being $32.0 \%$. This figure corresponds closely to the urinary uric acid as a percentage of the daily turnover, validating the calculation of the turnover rate of uric acid. In 9 healthy subjects urinary recovery of ${ }^{14} \mathrm{C}$ uric acid ranged from 63.0 to $75.5 \%$ of the injected dose, the mean value being $67 \cdot 8 \% \%^{15}$ With the 2 tailed, nonpaired Student's $t$ test the difference in urinary recovery of ${ }^{14} \mathrm{C}$-uric acid between the 2 groups is significant at a $\mathrm{P}$ value of $<0.001$.

In all but 2 of the 16 patients extrarenal excretion of uric acid was the major route of elimination. Figs. 2, 3, and 4 illustrate the recovery of ${ }^{14} \mathrm{C}$ in uric acid and in various breakdown products for 3 of the patients. The amount of ${ }^{14} \mathrm{C}$ recovered in the degradation products was $1 \cdot 45,2 \cdot 06$, and $3 \cdot 24$ times greater than that recovered in urinary uric

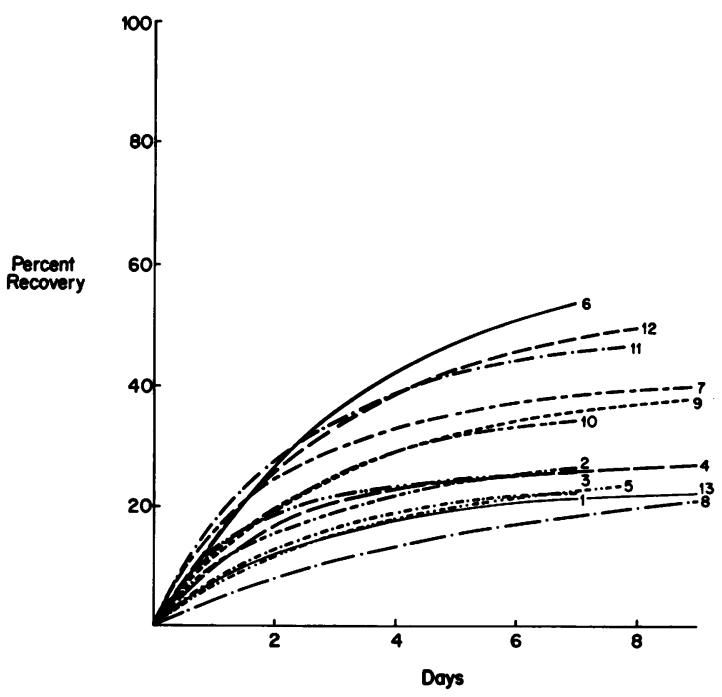

Fig. 1 The recovery from urine of intravenously injected ${ }^{14} \mathrm{C}$-uric acid in 13 patients with chronic renal disease. The index number refers to case number in Table 1. 


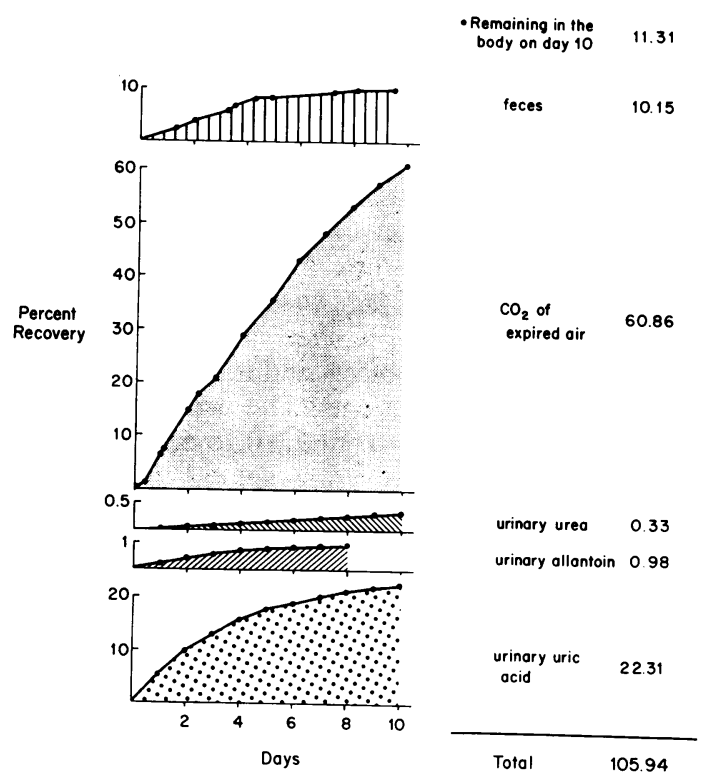

Fig. 2 Recovery of ${ }^{14} \mathrm{C}$-uric acid administered intravenously to a patient with chronic pyelonephritis (case 14 in Table I) (Reproduced by permission of Springer-Verlag, Berlin-Heidelberg ${ }^{15}$ ).

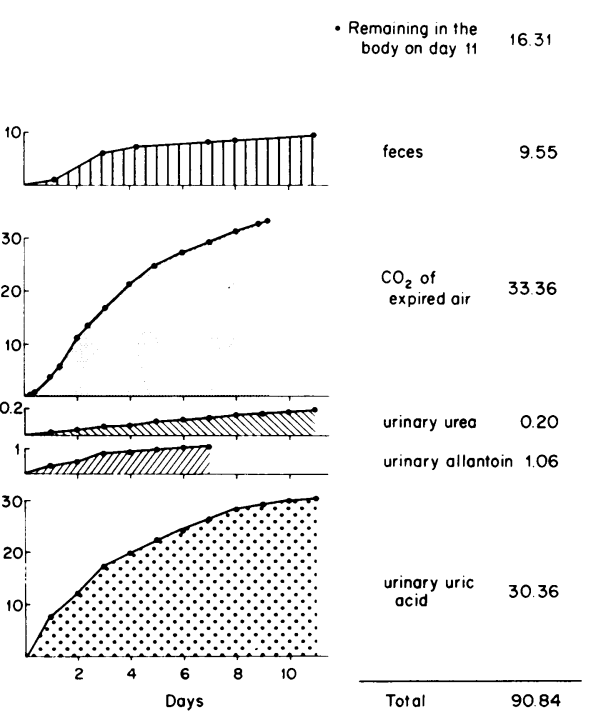

Fig. 3 Recovery of ${ }^{14} \mathrm{C}$-uric acid administered intravenously to a patient with diabetic glomerulosclerosis (case 15 in Table 1).

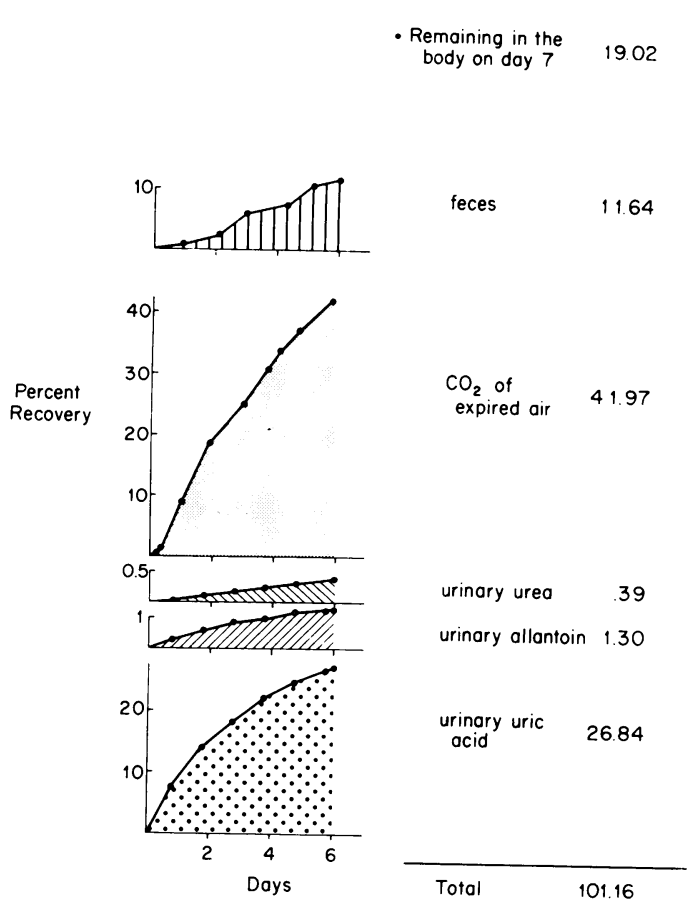

Fig. 4 Recovery of ${ }^{14} \mathrm{C}$-uric acid administered intravenously to a patient with chronic interstitial nephritis (case 16 in Table 1).

acid. As in normal man, carbon dioxide and ammonia are the principal uricolytic products.

\section{Discussion}

Although acute gouty arthritis has been reported infrequently and even questioned as a complication of chronic renal disease, personal experience suggests that intrinsic renal disease is the underlying cause of gout more frequently than is generally accepted. The true incidence of this sequel is difficult to assess with certainty. It will obviously depend on how thoroughly it is looked for, but frequently it is not possible to dissociate the role of such factors as hypertension and drugs that can contribute to hyperuricaemia by affecting uric acid excretion. In years past, before the era of efficacious treatment of hyperuricaemia, primary gout was not infrequently complicated by gouty nephropathy. There are, however, no firm data to suggest that primary hyperuricaemia will induce renal damage by urate crystal deposition within the renal parenchyma before it causes acute gouty arthritis.

The 20 reported cases represent the most clearcut examples of gout secondary to a primary renal disease among some 400 gout patients who have 
come to our attention during the past 20 years. It has been possible to define the nature of the renal disease with reasonable certainty, and the renal disease preceded the onset of gouty arthritis in all but 2 patients. Although the diagnosis of a welldefined nephropathy antedating gout strengthens the diagnosis of secondary renal gout, this is not an absolute requirement. Case 18 is an example in point. This patient developed acute gouty arthritis as the first manifestation of primary hyperparathyroidism with renal involvement.

Yü and Berger ${ }^{16}$ found that 253 of their 1700 patients with primary gout had evidence of varying degrees of renal involvement. Of these, 84 were considered to have primary intrinsic renal disease, such as chronic glomerulonephritis, chronic pyelonephritis, congenital renal disease, and proteinuria of underermined aetiology preceding gout by a mean of 15 years. Three patients had polycystic kidney disease and 2 women had onset of nephropathy during pregnancy. Although Yü and Berger considered these 84 cases to have primary gout with independently occurring intrinsic renal disease, it can be argued that at least some of their cases represent gout that is secondary to a nephropathy, especially since the onset of renal disease antedated gouty arthritis by many years in a good number of the patients.

As mentioned in the introduction, there are a few recognised entities in which gout occurs as a significant complication of chronic renal disease. Approximately $50 \%$ of patients with chronic lead nephropathy develop gouty arthritis. ${ }^{45}$ Other nephropathies associated with an increased incidence of gout include polycystic kidney disease ${ }^{6} 7$ and renal amyloidosis. ${ }^{3} \mathrm{~A}$ prevalence of hyperuricaemia of $50 \%$ and of gouty arthritis of $20 \%$ has been observed in a group of patients with Bartter's syndrome. ${ }^{11}$ It was suggested that systemic alkalosis, a prominent feature of Bartter's syndrome, may contribute to hyperuricaemia by decreasing the clearance of uric acid. Our study, together with the experience of Richet et al., ${ }^{3}$ suggests that any type of renal disease associated with prolonged hyperuricaemia may result in gouty arthritis.

Studies on uric acid metabolism showed a modest increase in the miscible pool of uric acid, averaging about $50 \%$. The production of uric acid was within the normal range, and thus renal failure does not affect extrarenal aspects of urate kinetics. All the patients studied had a decreased excretion of uric acid in the urine. The mean recovery of ${ }^{14} \mathrm{C}$-uric acid in the urine was $32.0 \%$. whereas in healthy subjects we have found an average recovery of $67.8 \%$ of injected ${ }^{14} \mathrm{C}$-uric acid in the urine. ${ }^{15}$ The difference between the daily turnover of uric acid and the uric acid excreted in the urine in a 24hour pericd represents that uric acid which has entered the gut in digestive juices. The recovery of ${ }^{14} \mathrm{C}$ in uricolytic breakdown products emphasises the enhanced enteral uricolysis that occurs as a compensatory measure in chronic renal disease with compromised renal excretion of uric acid.

The distribution of ${ }^{14} \mathrm{C}$ in various breakdown products indicates that carbon dioxide and ammonia are the principal degradation products of uric acid. Three patients in this study excreted 44,54 , and $71 \%$ of injected ${ }^{14} \mathrm{C}$ as carbon dioxide in expired air or in faeces. Almost all ${ }^{14} \mathrm{C}$ in faeces has been shown to be incorporated into bacteria. ${ }^{9}$ In other words, the bacterial flora utilises carbon dioxide derived from uric acid as a result of uricolysis. Carbon dioxide and ammonia are likewise the major breakdown products in individuals who have no overt renal disease. ${ }^{17}$ Small amounts of ${ }^{14} \mathrm{C}$-uric acid was recovered in urinary allantoin (from 0.4 to $4.7 \%$ ) and urinary urea (from 0.4 to $2 \cdot 5 \%$ ). Allantoic acid, another intermediary product in the breakdown of uric acid is inconsistently present in the urine. This compound is unstable, particularly at an acid $\mathrm{pH}$, and spontaneously degrades to glyoxylic acid and urea.

Although increased extrarenal excretion of uric acid assumes the major role in urate homoeostasis as renal function deteriorates, some patients with azotaemia show a remarkable adaptation in their renal handling of uric acid. Renal functional studies revealed that 2 of our patients (cases 8 and 12) had urate/inulin clearance ratios of $1: 3$. The findings conform with the experience of Steele and Rieselbach $^{18}$ that, with a reduction in glomerular filtration rate, there is a progressive increase in uric acid excretion per nephron. Their data show that residual nephrons of the chronically diseased kidney retain integrity of urate reabsorptive and secretory transport until inulin clearance has fallen to $15 \mathrm{ml} / \mathrm{min}$. Further impairment of renal function is associated with a marked increase in the fractional excretion of filtered urate. On the other hand not all our patients had an enhanced excretion of uric acid by residual nephrons. Patients with chronic lead nephropathy, for example, had very low urate clearances in relation to their corresponding glomerular filtration rates. A similar finding has been reported by Emmerson. ${ }^{14}$

With the elucidation of the mechanism of the acute attack of gout it is to be expected that this type of complication may occur during the course of renal disease of long duration. At present, when primary gout rarely leads to gouty nephropathy and primary renal disease is likely to be diagnosed at an early stage, the concomitant presentation of gout 
and azotaemia should lead the physician to consider that intrinsic renal disease may represent the underlying cause for hyperuricaemia.

\section{References}

1 Gresham G E, Keller M D. Hyperuricemia and chronic renal disease. J Chron Dis 1971; 23: 755-62.

2 Sarre H. Goutte secondaire à l'insuffisance rénale. In Travaux de Congrès International de la Goutte et de la Lithiase Urique. Paris: Evian, 1964; 245-55.

3 Richet G, Mignon F, Ardaillou R. Goutte secondaire des nephropathies chroniques. Presse Med 1965; 73: 633-8.

4 Emmerson B T. Chronic lead nephropathy: the diagnostic use of calcium EDTA and the association with gout. Aust Ann Med 1963; 12: 310-24.

5 Morgan J M, Hartley M W, Miller R E. Nephropathy in chronic lead poisoning. Arch Intern Med 1966; 118: 17-29.

- Newcombe D S. Gouty arthritis and polycystic kidney disease. Ann Intern Med 1973; 79: 605-6.

7 Martinez-Maldonado M. Polycystic kidney disease and hyperuricemia Ann Intern Med 1974; 80: 116.

8 Praetorius E. An enzymatic method for the determination of uric acid by ultraviolet spectrophotometry. Scand J Clin Lab Invest 1949; 1: 222-30.
Sorensen L B. The elimination of uric acid in man studied by means of ${ }^{14} \mathrm{C}$-labelled uric acid. Scand $J$ Clin Lab Invest 1960; 12 (suppl 54): 1-214.

10 Roe J E, Epstein J H, Goldstein N P. A photometric method for the determination of inulin in plasma and urine. J Biol Chem 1949; 178: 839-45.

11 Meyer W J, Gill J R, Bartter F C. Gout as a complication of Bartter's syndrome. A possible role for alkalosis in the decreased clearance of uric acid. Ann Intern Med 1975 83: 56-9.

12 Ball G V, Sorensen L B, Pathogenesis of hyperuricemia in saturnine gout. $N$ Engl J Med 1969; 280: 1199-202.

13 Ball G V, Sorensen L B. The pathogenesis of hyperuricemia and gout in sickle cell anemia. Arthritis Rheum 1970; 13: 846-8.

14 Emmerson B T. The renal excretion of urate in chronic lead nephropathy. Aust Ann Med 1965; 14: 295-303.

15 Sorensen L B. Excretion of uric acid in health and in disease. In Zöllner N, Gröbner W. eds. Handbuch der Inneren Medizin. Berlin, Heidelberg: Springer, 1976; 7: 142-63.

16 Yü T F, Berger L. Renal disease in primary gout: A study of 253 gout patients with proteinuria. Semin Arthritis Rheum 1975; 4: 293-305.

17 Sorensen L B. Degradation of uric acid in man. Metabolism 1959; 8: 687-703.

18 Steele T H, Rieselbach R E. The contribution of residual nephrons within the chronically diseased kidney to urate homeostasis in man. Am J Med 1967; 43: 876-86. 